\title{
EFFECT OF IBUPROFEN ALONE AND INCONJUGATION WITH VITAMIN E AND SELENIUM ON EXPERIMENTALLY INDUCED COCCIDIOSIS IN BROLIERS
}

\author{
M.A. Hafeez ${ }^{* 1}$, A. Sattar ${ }^{2}$, K. Ashraf ${ }^{1}$, M. Mehdi ${ }^{1}$, A. Rafique ${ }^{3}$, M.S. Mahmood ${ }^{4}$, F. Aslam ${ }^{5}$, I. Hussain ${ }^{5}$ and \\ M.R. $\mathrm{Zia}^{4}$ \\ ${ }^{1}$ Department of Parasitology, University of Veterinary and Animal Sciences, Lahore, Pakistan \\ ${ }^{2}$ Department of Pharmacology and Toxicology, University of Veterinary and Animal Sciences, Lahore, Pakistan \\ ${ }^{3}$ Department of Zoology, GC University Faisalabad, Pakistan \\ ${ }^{4}$ Institute of Microbiology, University of Agriculture, Faisalabad, Pakistan \\ ${ }^{5}$ Livestock and Dairy Development Department, Punjab \\ Corresponding author’s email: abdul.hafeez@uvas.edu.pk
}

\begin{abstract}
The aim of study was to determine the effect of $\left(\operatorname{Brufen}^{\mathrm{TM}}\right)$ alone and in conjugation with vitamin $\mathrm{E}$ and Selenium in broilers against coccidiosis. One hundred randomly allocated ( 25 birds in each group i.e., A, B, C \& D) day-old broiler chicks underwent the current trial. Group A, B and C were challenged with 60,000-70,000 sporulated oocysts of genus Eimeria at $21^{\text {st }}$ day of age. Group A and B were administered with (Brufen $\left.{ }^{\mathrm{TM}}\right)$ and combination of $\left(\mathrm{Brufen}^{\mathrm{TM}}\right)$ with vitamin $\mathrm{E}$ and Selenium $\left(\mathrm{E}-\mathrm{Sel}{ }^{\mathrm{TM}}\right) @ 100 \mathrm{mg} / \mathrm{kg}$ body weight and $1 \mathrm{ml} / 10$ liters of drinking water, respectively. Group C and D were kept as negative (infected \& un-medicated) and positive (un-infected \& un-medicated) controls, respectively. Therapeutic response was measured on the basis of mortality, oocysts count, weight gains, coccidial lesion scorings and weight of lymphoid organs. Maximum mortality was observed in group C (17/25), followed by group A (12/25), than in group B (8/25) post coccidial infection. Coccidial lesion scores and oocysts count were significantly lower in groups (A $\&$ B) administered with Ibuprofen. Moreover, maximum weight gain and reduced lymphoid organ to body weight ratio were also observed in chicken of group B as compared to A, C and D. The study suggested synergistic and enhanced protective response of Ibuprofen in combination with vitamin $\mathrm{E}$ and Selenium against chicken coccidiosis.
\end{abstract}

Key words: coccidiosis, ibuprofen, vitamin $\mathrm{E}$ and selenium, broilers, https://doi.org/10.36899/JAPS.2020.3.0074

Published online March 25, 2020

\section{INTRODUCTION}

Poultry industry is one of the most vibrant segment of agriculture industry of Pakistan. It plays an important role in bridging the gap between the supply and demand, as well as by contributing in total GDP (Mujahid et al., 2019). People restrain from investing in poultry industry due to the fear of high mortality associated with infectious as well as non-infectious diseases, still a loss for poultry sector (Peek and Landmanab, 2011; Fayyaz et al., 2019).

The increase in efficiency and productivity of poultry enterprises has greatly been hampered due to the health and managemental hazards faced by the farmers of developing countries. Pathogens like viruses, bacteria and parasites are concerned as promising causes of enteric sicknesses in poultry either unaccompanied (monocausal), in collaboration with diverse other microorganisms (multi-causal) or with non-infectious causes such as feed and /or management related factors (Rashid et al 2019). Among the parasitic diseases, coccidiosis is an important protozoan disease of poultry (McDougald. 2003). Coccidiosis, caused by nine species of apicomplexan protozoan including E. tenella, E. necatrix E. acervulina, E. brunetti, E. praecox, E. hagani, E. maxima, E. mitis and E. mivati (Soulsby. 1982: Chapman et al, 2013). This disease is causing huge economic losses especially in United States, which is around US\$3 billion annually while in Pakistan in billions of US\$ loss in incurred annually due to increased mortality rates, decreased weight, gain, increased medication costs, and increased feed conversion rate (Kadykalo et al. 2018). For many years, use of anticoccidial chemotherapy has been the mainstay of controlling coccidiosis in the broiler industry and played a pivotal role in the growth of this industry (Allen and Fetterer, 2002: Sandra et al. 2019). However, development of anticoccidial resistance and insufficient immunity elicited after vaccination has threatened the economic stability. Due to menace of coccidiosis to poultry industry, there is a need to investigate alternative options for the control of coccidiosis. Non-steroidal antiinflammatory drugs (NSAIDs) present themselves as a possible adjunct for the treatment of coccidiosis (Sosters et al, 2013). Ibuprofen (a NSAID) is a potential drug that inhibits cyclooxygenase pathway of arachidonic acid metabolism, thus blocks the production of prostaglandins $(\mathrm{PG})$ those have pro-inflammatory and 
immunosuppressive properties in coccidial infection (Vermeulin et al. 2004; Sun et al., 2019). Control of coccidiosis through chemotherapy is still a dominating approach (Anjum 1997: Hussain et al., 2019) as witnessed by Vermeulin et al. (2004) and in combination with immune stimulants need to be browsed, for which the present study is demarcated.

Supplementation with Selenium and vitamin E reduces mortality and increases body weight gain of chicken infected with E. tenella (Colnago et al. 1984; Dlouha et al, 2008). Vitamin E (alpha tocopherol) appears to have a significant effect on the immune system. This is a natural biological antioxidant, which enhances immune system by stimulating glutathione peroxides activity of circulating neutrophils and macrophages. It stimulates the activity of T-lymphocytes as well as maintains blood selenium in an active form and prevents its loss from the body (Leeson and Summers, 2001). Moreover, vitamin E reduces the free radical production and pathological lesions formation during inflammation (Tappel, 1972). Vitamin E also plays an important role in the stimulation of the immune system against certain diseases like coccidiosis and colibacillosis (El-Boushy, 1988). Selenium is required for the proper functioning of the glutathione peroxidase (antioxidant enzymes), which eliminates free radicals and per oxides produced during normal metabolism and pathological conditions (Rotruck et al. 1973: Shlig 2009).

Despite, a lot of research, carried out in prevention and control, coccidiosis is still considered as the major health as well as economic problem, particularly in chickens. Ibuprofen $\left(\right.$ Brufen $^{\mathrm{TM}}$ ) alone and in combination with Vitamin E and Selenium (E-Sel ${ }^{\mathrm{TM}}$ ) was used in experimentally induced broilers against coccidiosis to study the effects on mortality, oocysts shedding, weight gain, coccidial lesion scores, development of lymphoid organ and immune responses. This research may contribute a lot to poultry farmers for selecting an effective method of new treatment for controlling coccidiosis in their flocks.

\section{MATERIALS AND METHODS}

Collection and Examination of Materials: A total of seven hundred chicken guts suspected with outbreaks of coccidiosis were collected from different commercial poultry farms in and around Faisalabad city. These gut samples were opened in clean environment of the undergraduate laboratory, Department of Clinical Medicine \& Surgery. The fecal material was scrapped off in the glass petri dishes and subjected to microscopic examination by direct smears (Soulsby, 1982). The positive samples were used to measure the size of the oocysts with a calibrated microscope. The contents obtained from these samples were placed and thoroughly mixed in $2.5 \%$ potassium dichromate solution and kept overnight (Hafeez et al. 2006; Abbas et al., 2019).

Extraction and Sporulation of Oocysts: The positive gut contents were subjected to salt flotation technique to determine oocysts concentration (Ryley et al. 1976). Oocysts obtained from saturated salt solution were poured into distilled water to bring the specific gravity below 1.03. The oocysts purification was performed by centrifugation at $1500 \mathrm{~g}$ for 5 minutes and transferred into $2.5 \%$ potassium dichromate solution in petri dishes, incubated at $30-32^{\circ} \mathrm{C}$ and $60-80 \%$ humidity for 48 hours (Hafeez et al. 2006). Sporulated oocysts were stored at $\left(4^{\circ} \mathrm{C}\right)$ for further use. Counting of sporulated oocysts was done by modified McMaster oocysts counting technique (Theinpont et al. 1979) and infective dose (65000 viable oocysts) was prepared.

Experimental Design: A total of one hundred day-old disease free broiler (Hubbard $®$ ) chicks were procured from renowned company. The chicks were brooded and reared under standard managemental conditions in a clean disinfected experimental shed. At $5^{\text {th }}$ day of age, chicks were randomly divided into four equal groups $(25$ chicks in each) designated as A, B, C and D. Feed (with drawl) and water (ad-libitum) was offered to all the groups. The birds in groups $\mathrm{A}, \mathrm{B}$ and $\mathrm{C}$ were given $2 \mathrm{ml}$ of inoculum containing 60,000-70,000 (average 65,000) viable coccidian-oocysts of Eimeria (E) E. tenella, E. maxima, E. acervulina and E. necatrix (local isolates) directly into the crop, identified on the basis of their shape, size, predilection site as well as confirmed by PCR using species specific primers (Allen and Fetterer 2002; Fernendaz et al. 2003). The fecal examination of the experimental birds of each treatment group was started on $2^{\text {nd }}$ day post-inoculation. These groups were subjected to the following treatments:

Group A- (Infected and medicated) treated with Ibuprofen (Brufen suspension ${ }^{\mathrm{TM}}$, Abbot Lab. Pakistan Ltd.) @100mg per kg body weight orally for 5 days post challenge.

Group B-(Infected and medicated) treated with Ibuprofen (Brufen suspension ${ }^{\mathrm{TM}}$, Abbot Lab. Pakistan Ltd.)@100mg per kg body weight orally for 5 days and vitamin $\mathrm{E}$ and Selenium (E-Sel ${ }^{\mathrm{TM}}$ suspension, International Corp. for Manufacturing of Vet. Medicines, Amman, Jordan)@ $1 \mathrm{mg} / \mathrm{kg}$ in drinking water for five consecutive days post challenge.

Group C- kept as Infected and non-medicated control (Negative control)

Group D- kept as Non-infected un-medicated control (Positive control).

Parameters studied: Mortality was observed on daily basis, Lesion scoring was performed during (by post mortem examination of dead) and after the challenge experiment (slaughtering and postmortem of survived 
chicks) by Johnson and Reid (1970). The oocysts shedding (by collecting the whole feces) and weight gain was determined after every day while effects on lymphoid organs were assessed weekly.

Statistical Analysis: Data were collected and analyzed by "Kruskal-Wallis H" test using SPSS. As this test is Nonparametric so data was interpreted by self-decision keeping in view parameters, such as Percentage Mortality, Mean Values, Standard Deviation, Standard Error and P- values. The Mann-Whitney test was also used for the determination of significance of each group rather than all groups. The mean values and standard error of means for each parameter were calculated. Statistical package for social sciences (SPSS Inc., Chicago, IL, USA, 1999) used for interpretation of results.

\section{RESULTS AND DISCUSSION}

NSAIDs present themselves as a beneficial remedy for digestive parasitic infections in broiler production systems (Allen 2000; Livington, 2000). NSAIDs mechanism of action supposed to be prostaglandin (PG) dependent, since an increased PG biosynthesis might be suspected in coccidial infections, mediated by a nitric oxide (NO) induced increased activity of Cyclo-oxygenese-2 (COX2) (Livington, 2000). Therefore, in many studies NSAIDs are considered to be the candidate molecule in treatment of coccidiosis in broiler birds (Allen and Fetterer 2002; Vermeulin et al. 2004). In parasitic infection of mammals, NSAIDs have been proved to be effective, since they can restore the IL-2 levels during protozoan infections. Furthermore, PGs are often associated with parasite-induced immunosuppression via inhibition of IL2 secretion.

The key endeavor of the present project was to explore the therapeutic potential of NSAIDs alone or in combination with vitamin $\mathrm{E}$ and selenium in controlling the parasitic infection of vertebrates with protozoan protists in local environment. The clinical signs appeared in groups $\mathrm{A}, \mathrm{B}$, and $\mathrm{C}$ post challenge are correlated to the findings of Clarke, 1979 and Carbajal et al. (2010) who observed bloody faeces after infection. Highest mortality $(17 / 25)$, was observed in group $\mathrm{C}$ (negative control) as compared to group A (12/25) and group B (8/25). No mortality was observed in group D (positive control). These outcomes are in accordance with the findings of Calnek et al. (1997) and Ashraf (1994) found higher mortality in Infected and unmedicated control group than the medicated one (Diaveridine and sulphaquinoxaline with and without supplementation of vitamin A and $\mathrm{K}$ ). No mortality was found in uninfected and unmedicated control group. Recovery from coccidiosis increased due to the use of sulphaquinoxaline in combination with vitamin $\mathrm{A}$ and vitamin $\mathrm{K}$.

Production of lesions in birds during coccidial infection depends upon the age and severity of infection as reported by Costa and Avila (1996) and McDougald et al. (1997). The lesion scores recorded in the slaughtered birds of infected groups A, B and C were found zero on day one \& two which gradually increased till the sixth day that started to decline on $7^{\text {th }}$ day (Table 2). In group $\mathrm{D}$, minimal/no coccidiosis lesions were observed up till the end of experiment. Statistical analysis showed that there was a significant difference $(\mathrm{P} \leq 0.05)$ among mean lesion scores of infected groups. Lowest lesion scores were observed in group B as compared to group A, while group $\mathrm{C}$ showed highest lesion scores (Table 2). Findings in group B revealed that Ibuprofen in combination with vit. $\mathrm{E}$ and selenium is helpful in reducing caecal lesion scores in birds infected with coccidiosis. These results are substantiated by the findings of Vermeulin et al. (2004) and Carbajal et al. (2010) the positive effect of different levels of arginine and vitamin $\mathrm{E}$ was observed on lesion scoring. Birds fed higher levels of vitamin $\mathrm{E}$ and Arginine had a better immune response post eimeria challenge suggested that Vitamin E is associated with lowering the lesion score in poultry birds 14 days of post infection. Oocyst count in groups $\mathrm{A}, \mathrm{B}$, and $\mathrm{C}$ was calculated first on day 3 post challenge $\left(24^{\text {th }}\right.$ day of age $)$ which progressively increased till $30^{\text {th }}$ day of age (Table 1). Afterwards oocysts per gram (OPG) count declined progressively till the end of experiment ( $33^{\text {rd }}$ day of age). Only a few oocysts were found in the group D at the end of the experiment. The statistical analysis showed that the difference between the OPG counts of medicated groups as compared to infected control $(\mathrm{C})$ was significant $(\mathrm{P} \leq 0.05)$. OPG count reduction was more pronounced in group $\mathrm{B}$ than group $\mathrm{A}$ (Table 1). The superscripts in small letters are indicative of significant differences between the oocysts output and compared with only oocysts output on different days and with different groups. Due to the anticoccidial activity of Brufen as well as immune stimulation by Vit. E and Selenium the OPG was less in group A (medicated) but infected control devoid of such privilege and produced more number of the oocyst leading to the propagation of disease. The average body weight gain (grams) record was maintained from day $21^{\text {st }}$ up to the termination of experiment. The superscripts in capital letters are indicative of significant differences between the weight gains and compared with only weight gain on different days and with different groups. In groups $\mathrm{D}$ and $\mathrm{B}$, maximum gains in weights was observed, as compared to group A. Group C gained lowest weight as it was infected control (Table 1). The difference between the weight gains of test groups as compared to infected control 
Table - 1: Average oocyst per gram of faeces and body weight gain $(\mathrm{gms})$ in different groups $(n=4)$ evaluated for the therapeutic effects of Ibuprofen $\left(\right.$ Brufen $\left.^{\mathrm{TM}}\right)$ alone and in conjugation with vitamin $E$ and selenium $\left(E-S E L^{\mathrm{TM}}\right)$ in experimentally induced coccidiosis

\begin{tabular}{|c|c|c|c|c|c|c|c|c|}
\hline \multirow{2}{*}{ Group } & \multirow{2}{*}{ Parameters studied } & \multicolumn{7}{|c|}{ Age (Days) } \\
\hline & & 21 & 22 & 23 & 24 & 25 & 26 & 27 \\
\hline \multirow[t]{2}{*}{$\mathbf{A}$} & Oocyst count & -------- & ------- & ------- & ------- & $9800 \pm 450^{b}$ & $17800 \pm 624^{b}$ & $22800 \pm 788^{b}$ \\
\hline & Weight gain (gms) & $464 \pm 1.44^{\mathrm{B}}$ & $505 \pm 1.56^{\mathrm{B}}$ & $549 \pm 2.46^{\mathrm{B}}$ & $606 \pm 2.86^{\mathrm{B}}$ & $634 \pm 2.88^{\mathrm{B}}$ & $680 \pm 2.98^{\mathrm{B}}$ & $746 \pm 2.99^{\mathrm{B}}$ \\
\hline \multirow[t]{2}{*}{ B } & Oocyst count & --------- & -------- & -------- & -------- & $10600 \pm 488^{c}$ & $16300 \pm 578^{c}$ & $20600 \pm 790^{\circ}$ \\
\hline & Weight gain (gms) & $490 \pm 1.80^{\mathrm{C}}$ & $552 \pm 1.90^{\mathrm{C}}$ & $586 \pm 2.10^{\mathrm{C}}$ & $626 \pm 2.60^{C}$ & $662 \pm 2.68^{\mathrm{C}}$ & $698 \pm 2.78^{\mathrm{C}}$ & $758 \pm 2.80^{\mathrm{C}}$ \\
\hline \multirow[t]{2}{*}{$\mathrm{C}$} & Oocyst count & ------- & -------- & -------- & -------- & $14600 \pm 790^{\mathrm{a}}$ & $20800 \pm 749^{a}$ & $40800 \pm 798^{\mathrm{a}}$ \\
\hline & Weight gain (gms) & $440 \pm 1.57^{\mathrm{B}}$ & $475 \pm 1.60^{\mathrm{A}}$ & $505 \pm 1.62^{\mathrm{A}}$ & $530 \pm 1.80^{\mathrm{A}}$ & $565 \pm 1.88^{\mathrm{A}}$ & $592 \pm 1.92^{\mathrm{A}}$ & $616 \pm 2.30^{\mathrm{A}}$ \\
\hline \multirow[t]{2}{*}{ D } & Oocyst count & ------- & -------- & -------- & -------- & $80 \pm 12.60^{\mathrm{d}}$ & $118 \pm 5.60^{\mathrm{d}}$ & $310 \pm 8.60^{\mathrm{d}}$ \\
\hline & Weight gain (gms) & $480 \pm 1.20^{\mathrm{E}}$ & $558 \pm 1.600^{\mathrm{E}}$ & $588 \pm 2.20^{\mathrm{E}}$ & $618 \pm 2.28^{\mathrm{C}}$ & $668 \pm 2.53^{C}$ & $696 \pm 1.98^{\mathrm{C}}$ & $755 \pm 1.88^{\mathrm{C}}$ \\
\hline
\end{tabular}

\begin{tabular}{|c|c|c|c|c|c|c|c|}
\hline \multirow{2}{*}{ Group } & \multirow{2}{*}{ Parameters studied } & \multicolumn{6}{|c|}{ Age (Days) } \\
\hline & & 28 & 29 & 30 & 31 & 32 & 33 \\
\hline \multirow[t]{2}{*}{$\mathbf{A}$} & Oocyst count & $24300 \pm 796^{\mathrm{b}}$ & $28600 \pm 814.8^{b}$ & $30200 \pm 714.8^{b}$ & $14800 \pm 658.7^{\mathrm{b}}$ & $7806 \pm 648.7^{b}$ & $3206 \pm 608.7^{b}$ \\
\hline & Weight gain (gms) & $779 \pm 2.99^{\mathrm{B}}$ & $828 \pm 2.09^{\mathrm{B}}$ & $864 \pm 2.12^{\mathrm{B}}$ & $908 \pm 2.02^{\mathrm{B}}$ & $952 \pm 2.01^{\mathrm{B}}$ & $988 \pm 2.40^{\mathrm{B}}$ \\
\hline \multirow[t]{2}{*}{ B } & Oocyst count & $23200 \pm 798^{c}$ & $25600 \pm 823.8^{c}$ & $28400 \pm 723.8^{\mathrm{c}}$ & $13200 \pm 76.94^{\mathrm{c}}$ & $7030 \pm 706.94^{\mathrm{c}}$ & $2830 \pm 606.4^{\mathrm{c}}$ \\
\hline & Weight gain (gms) & $798 \pm 2.88^{\mathrm{C}}$ & $834 \pm 2.18^{\mathrm{C}}$ & $874 \pm 2.06^{\mathrm{C}}$ & $929 \pm 2.16^{\mathrm{C}}$ & $972 \pm 2.06^{\mathrm{C}}$ & $1055.2 \pm 2.60^{C}$ \\
\hline \multirow[t]{2}{*}{$\mathbf{C}$} & Oocyst count & $52600 \pm 806^{\mathrm{a}}$ & $64800 \pm 811.9^{a}$ & $68200 \pm 801.9^{a}$ & $39600 \pm 825.19^{\mathrm{a}}$ & $18700 \pm 815.09^{\mathrm{a}}$ & $9768 \pm 810.9^{a}$ \\
\hline & Weight gain (gms) & $668 \pm 2.38^{\mathrm{A}}$ & $692 \pm 2.38^{\mathrm{A}}$ & $732 \pm 1.51^{\mathrm{A}}$ & $762 \pm 1.50^{\mathrm{A}}$ & $798 \pm 1.45^{\mathrm{A}}$ & $842 \pm 1.00^{\mathrm{A}}$ \\
\hline \multirow[t]{2}{*}{ D } & Oocyst count & $398 \pm 8.60^{\mathrm{d}}$ & $450 \pm 16.80^{\mathrm{d}}$ & $580 \pm 18.80^{\mathrm{d}}$ & $767 \pm 14.90^{\mathrm{d}}$ & $680 \pm 13.00^{\mathrm{d}}$ & $598 \pm 12.60^{\mathrm{d}}$ \\
\hline & Weight gain (gms) & $785 \pm 1.88^{\mathrm{C}}$ & $840 \pm 1.90^{\mathrm{C}}$ & $882.0 \pm 2.55^{\mathrm{C}}$ & $932.0 \pm 2.58^{\mathrm{C}}$ & $975.0 \pm 2.48^{\mathrm{C}}$ & $1067 \pm 2.62^{C}$ \\
\hline
\end{tabular}

Values are mean values \pm SD. Within column, values having different superscripts are significantly $(p \leq 0.05)$ different

The superscripts in small letters are indicative of significant differences between the oocysts output and compared with only oocysts out on different days and with different groups

The superscripts in capital letters are indicative of significant differences between the weight gain (gms) and compared with only weight gain on different days and with different groups

Table-2: Lesion score in different groups $(\mathrm{n}=4)$ evaluated for the therapeutic effects of Ibuprofen $\left(B r u f e n^{\mathrm{TM}}\right)$ alone and in combination with vitamin $\mathrm{E}$ and selenium $\left(E-S E L^{\mathrm{TM}}\right)$ in experimentally induced coccidiosis

\begin{tabular}{|c|c|c|c|c|c|c|c|c|c|c|c|c|c|c|c|c|}
\hline \multirow{3}{*}{ Groups } & \multicolumn{16}{|c|}{ Lesion Score on days } \\
\hline & \multicolumn{3}{|c|}{1} & \multicolumn{3}{|c|}{2} & \multicolumn{3}{|c|}{3} & \multicolumn{3}{|c|}{4} & \multicolumn{2}{|r|}{5} & \multirow{2}{*}{$\begin{array}{c}6 \\
\mathrm{M} C\end{array}$} & 7 \\
\hline & $\mathbf{U}$ & M & $\mathrm{C}$ & & $\mathbf{M}$ & $\mathbf{C}$ & & U M C & & & $\mathbf{U} \mathbf{M C}$ & & & $\mathrm{U} \mathbf{M} \mathbf{C}$ & & U M C \\
\hline $\mathrm{A}$ & 0 & 0 & 0 & 0 & 0 & 0 & $0.25^{\mathrm{c}}$ & $0.25^{\mathrm{c}}$ & $0.50^{c}$ & $0.50^{\mathrm{c}}$ & $0.50^{c}$ & $0.75^{\mathrm{c}}$ & $0.75^{\mathrm{c}}$ & $0.75^{\mathrm{c}} 1.00^{\mathrm{c}}$ & $0.25^{\mathrm{c}} 0.25^{\mathrm{c}} 0.50^{\mathrm{c}}$ & $\begin{array}{lll}0.10^{\mathrm{c}} & 0.12^{\mathrm{c}} & 0.15^{\mathrm{c}}\end{array}$ \\
\hline B & 0 & 0 & 0 & 0 & 0 & 0 & $0.14^{\mathrm{b}}$ & $0.15^{\mathrm{b}}$ & $0.10^{\mathrm{b}}$ & $0.15^{b}$ & $0.17^{\mathrm{b}}$ & $0.25^{\mathrm{b}}$ & $0.18^{b}$ & $0.25^{\mathrm{b}} 0.25^{\mathrm{b}}$ & $0.10^{\mathrm{b}} \quad 0.15^{\mathrm{b}} \quad 0.10^{\mathrm{b}}$ & $0.07^{\mathrm{b}} \quad 0.10^{\mathrm{b}} \quad 0.08^{\mathrm{b}}$ \\
\hline $\mathrm{C}$ & 0 & 0 & 0 & 0 & 0 & 0 & $1.50^{\mathrm{a}}$ & $1.75^{\mathrm{a}}$ & $1.75^{\mathrm{a}}$ & $2.25^{\mathrm{a}}$ & $2.50^{\mathrm{a}}$ & $2.75^{\mathrm{a}}$ & $3.25^{\mathrm{a}}$ & $3.50^{\mathrm{a}} \quad 3.75^{\mathrm{a}}$ & $3.75^{\mathrm{a}} 4.00^{\mathrm{a}} 3.75^{\mathrm{a}}$ & $3.00^{\mathrm{a}} \quad 3.50^{\mathrm{a}} \quad 3.75^{\mathrm{a}}$ \\
\hline $\mathrm{D}$ & 0 & 00 & 0 & 0 & 0 & 0 & $0.05^{\mathrm{d}}$ & $0.00^{\mathrm{d}}$ & $0.01^{\mathrm{d}}$ & $0.07^{\mathrm{d}}$ & $0.02^{\mathrm{d}}$ & $0.00^{\mathrm{d}}$ & $0.00^{\mathrm{d}}$ & $0.01^{\mathrm{d}} \quad 0.05^{\mathrm{d}}$ & $0.00^{\mathrm{d}} \quad 0.10^{\mathrm{d}} \quad 0.0^{\mathrm{d}}$ & $0.05^{\mathrm{d}} 0.02^{\mathrm{d}} \quad 0.04^{\mathrm{d}}$ \\
\hline
\end{tabular}

$\mathbf{U}=$ Upper part of intestine $\mathbf{M}=$ Middle part of intestine $\mathbf{C}=$ Ceacal tonsils

V. Mild $=0-0.5 \quad$ Mild $=0.51 .0 \quad$ Moderate $=1.0-1.5 \quad$ Severe $=1.5-2.5 \quad$ V. Severe $=2.5-4.0$

Values are mean values, within column, values having different superscripts are significantly $(p \leq 0.05)$ different. 
Figure-I Average body weight ratio of lymphoid organs in different groups $(\mathrm{n}=4)$ represented in terms of $\mathrm{gm} / \mathrm{kg}$ B.w, evaluated for the therapeutic effects of Ibuprofen (Brufen ${ }^{\mathrm{TM}}$ ) alone and in combination with vitamin $E$ and selenium $\left(E-S E L^{T M}\right)$ in experimentally induced coccidiosis.

(group C) and un-infected control (group D) was significant $(\mathrm{P} \leq 0.05)$. In coccidial infection there is a significant decrease in weight gains of affected birds might be due to the damage to the epithelial cells of intestines. The cells got revived after Brufen's administration in groups $\mathrm{A}$ and $\mathrm{B}$, and gained weight normally as stress of disease was subsided. The results of group B depicted that new treatment protocol (Brufen + E-Sel) proved successful in reducing the severity of disease as described also by Vermeulin et al. 2004. Using Brufen, There is the hypertrophy and cellular infiltration of the lymphoid organs, which resulted into the increase in organ body weight ratio in infected chicks (Hafeez 2004). Similar results has been found in the current study in medicated groups A and B that revealed comparatively better results on organ body weight ratio.

Organ body weight ratio of all groups A, B, C and D were calculated (Figure. I). The values showed that spleen, thymus, bursa of Fabricius and caecal tonsils of group $\mathrm{C}$ were having more weights (increased) than those of groups A, B \& D (remained normal). Statistical analysis showed that there was a significant difference $(P$ $\leq 0.05$ ) among organ body weight ratio of groups $\mathrm{A}, \mathrm{B}$ and $\mathrm{D}$ as compared to $\mathrm{C}$. Group $\mathrm{C}$ was having more organ body weight ratio as compared to groups $\mathrm{A}, \mathrm{B}$ and $\mathrm{D}$ (Figure-I). A non-significant difference was observed among lymphoid organ weights of groups A, B and D (P $>0.05)$. Ibuprofen had an anticoccidial effect results in production NO which was toxic for the Eimeria species, then a decrease in lesion scores with no significant effect on oocysts shedding in the feces was observed. These findings are fairly linear with studies of Vermeulin et al. 2004.

In nut shell the present gadget in prophylactic control of coccidiosis using NSAIDs exclusively and in combination with supplements of vitamin $\mathrm{E}$ and selenium may serve as useful control measure in treating protozoal infection in poultry. The addition of vitamin $\mathrm{E}$ and Selenium may enhance the ability of birds to combat the invasion of Eimeria species (immunosuppressive) and may also enhances the effectiveness of Ibuprofen in reducing severity of disease by minimizing the immunosuppressive properties. Results of this study may contribute a lot for poultry farmers seeking an effective method for controlling coccidiosis in their flocks by using this new treatment protocol.

Conflict of Interest: The authors have declared no conflict of interest.

Compliance with Ethics Standards: All experimental protocols concerning the handling of birds were in accordance with the requirements of the Institutional Animal Care and Use Committee at University of Agriculture Faisalabad.

\section{REFERENCES}

Abbas A., R.Z. Abbas, M.K. Khan, M.A. Raza, M.S. Mahmood, M.K. Saleemi, T. Hussain, J.A. Khan and Z.U.D. Sindhu (2019). Anticoccidial effects of Trachyspermum ammi (Ajwain) in broiler chickens. Pakistan Vet. J., 39:301-304.

Allen, P.C. (2000). Effects of treatments with cyclooxygenase inhibitors on chickens infected with Eimeria acervulina. Poult. Sci. 79: 12511258.

Allen, O.C. and R. H. Fetterer (2002). Recent advances in biology and immunobiology of Eimeria species and diagnosis and control of infection with these coccidian parasites of poultry. Clin. Microbiol. Rev. 15: 58-65.

Anjum, S. A. (1997). Studies on haemorrhagic syndrome in chickens experimentally infected with coccidiosis and treated with Embazine. M.Sc. Thesis, Deptt. of Parasitology. Univ. Agri., Faisalabad, Pakistan.

Ashraf, M. (1994). Effect of induced coccidiosis on growth and blood parameters in commercial quails. M.Sc. Thesis, Deptt. of Parasitology, Univ. Agri., Faisalabad, Pakistan. 
Calnek, B.W., H.J. Barnes, C. W. Beard, L. R., McDougald and Y. M. Saif. (1997). Diseases of poultry, $10^{\text {th }}$ ed. Mosby Woife, USA. Pp 865-883

Carbajal, C.P., D. Caldwell, M. Farnell, K. Stringfellow, S. Pohl, G. Casco, A. Pro-Martinez and C. A. RuizFeria (2010). Immune response of broiler chickens fed different levels of arginine and vitamin $\mathrm{E}$ to a coccidiosis vaccine and Eimeria challenge. Poult. Sci. 89:1870-1877.

Chapman, H.D., J.R. Barta, D. Blake, A. Gruber, M. Jenkins, N.C. Smith, X. Suo and F.M. Tomley (2013). A selective review of advances in coccidiosis research. Advan. in Parasitol. 83:93171

Clarke, P. L. (1979). Coccidial infection with Eimeria tenella and caecal defecation in chicks. British Poult. Sci.; 20: 317-322.

Colnago, G.L., L.S. Jensen and P. L. Long (1984). Effect of selenium and vitamin $\mathrm{E}$ on the development of immunity to coccidiosis in chickens. Poult. Sci. 6: 1136-1143.

Costa, C.A. and V.S. Avilla (1996). Effect of bird age, reuse and management of litter on coccidiosis in broilers. Poult. Abstract 23: 401-403.

Dlouha, G., S. Sevcekova., A. Dokoupilova and L. Zita. (2008). Effect of Dietary Selenium Sources Peroxidase and Glutathione in Broiler. Biochimica et. Biophysica Acta, 497: 218-224

EL-Boushy. (1988). Vitamin E affects viability, immune response of Poultry. Feed St. 60: 20-26.

Fayyaz M., M.S. Khan, F.A. Joyia and M.A. Zia (2019). Sequence and structural analysis of synthetic VP2 antigenic protein as a subunit vaccine candidate against very virulent strains of infectious bursal disease virus. Pakistan Vet. J., 39:106-110.

Fernandez, S., A.H. Pagotto, M.M. Furtado, A.M. Katsuyama, A.M. Madeira and A.A. Gruber (2003). Multiplex PCR assay for the simultaneous detection and discrimination of the seven Eimeria species that infect domestic fowl. Parasitol. 127:317-325.

Hafeez, M. A. (2004). Immunogenic characterization of gametocyte antigen(s) as vaccine against coccidiosis in poultry. PhD Dissertation Deptt. of Parasitology, Uni. Agri., Faisalabad

Hafeez, M.A., M. Akhtar and I. Hussain (2006). Protective effect of egg-propagated Eimeria tenella (local isolates) gametocytes as vaccine(s) against mixed species of coccidia in chicken. Parasitol. Res. 98:539-544.

Hussain R., F. Ali, A. Rafique, A. Ghaffar, G. Jabeen, M. Rafay, S. Liaqat, I. Khan, R. Malik, M.K. Khan, M. Niaz, K. Akram and A. Masood (2019). Exposure to sub-acute concentrations of glyphosate induce clinicohematological, serum biochemical and genotoxic damage in adult cockerels. Pakistan Vet. J., 39:181-186.

Johnson, J. and W. M. Reid (1970). Anticoccidial drugs: Lesion scoring techniques in battery and floorpen experiments with chickens. Exp. Parasitol. 28:30-36.

Kadykalo S., T. Roberts, M. Thompson, J. Wilson, M. Lang and O. Espeisse (2018). The value of anticoccidials for sustainable global poultry production. Int. J. Antimicrobial Agents 51(3):304-310.

Leeson, S. and J.D. Summers (2001). Nutrition of the Chicken. $4^{\text {th }}$ ed. International Book Distributing Co.; 228-232.

Livington, A. (2000). Mechanism of action of nonsteroidal anti-inflammatory drugs. Vet. Clinical North American Small Animal Pract. 30: 773-81.

McDougald, L.R., L. Fuller and R. Mattiello (1997). A survey of coccidia on 43 poultry farms in Argentina Department of Poultry Science Georgia, Athens, GA-30602, USA.

McDougald, L.R. (2003). Protozoal Infections. In: Diseases of Poultry. $11^{\text {th }}$ ed., Saif, YM, Barnes HJ, Gilsson JR, Fadly AM, Swayne, DE. (Eds). The Iowa State Press University, A Blackwell Publishing Company Ames, USA.

Mujahid H., A.S. Hashmi, M.Z. Khan, M. Tayyab and W. Shezad (2019). Protective effect of yeast sludge and whey powder against ochratoxicosis in broiler chicks. Pakistan Vet. J., 39:588-592.

Peek, H.W. and W.J.M. Landmanab (2011). Coccidiosis in poultry: Anticoccidial products, vaccines and other prevention strategies. Vet. Quart. 31; 143 161.

Rashid M., A. Haroon, B. Amir , I. R. Muhammad, A. H. Muhammad, H. Tahir , M. Sohail and Y. Hong. (2019). Assessing the prevalence and economic significance of coccidiosis individually and in combination with concurrent infections in Pakistani commercial poultry farms. Poult. Sci. 98: 1167-1175.

Rotruck, J.T., A.L. Pope, H.E. Ganther, A.B. Swanson, D.C. Hafeman, and W.G. Hoekstra (1973). Selenium: biochemical role as a component of glutathione peroxidase. Sci. 179: 588-590.

Ryley, J.F., R. Meade, J. Ifazalburst and T.E. Robinson (1976). Methods in coccidiosis research, separation of oocysts from faeces. Parasitol. 73: 311-326.

Sandra N., H.D. Chapman, and P.M. Selze (2019). Anticoccidial drugs of the livestock industry. Parasitol. Res., 118: 2009-2026

Sostres, C., C. J. Gargallo and A. Lanas (2013). Nonsteroidal anti-inflammatory drugs and upper and lower gastrointestinal mucosal 
damage," Arthritis Research \& Therapy, 15: 3, p. S3,

Shlig, A.A. 2009. Effect of Vitamin E and Selenium Supplement in Reducing Aflatoxicosis on Performance and Blood Parameters in Broiler Chicks. Iraqi J. Vet. Sci. 23:97-103.

Soulsby, E.J.L. (1982). Helminthes, Arthropods and Protozoa of Domestic Animals. $7^{\text {th }}$ ed., Bailliere Tindall, London.

Sun N., P. Sun, N. Xie, A. Khan, Y. Sun, K. Fan, W. Yin and H. Li (2019). Antiviral and immunomodulatory effects of dipotassium glycyrrhizinate in chicks artificially infected with infectious bursal disease virus. Pakistan Vet. J., 39:43-48.

Tappel, A.I. (1972). Vitamin E and free radical peroxidation of lipids. Annals of The New York Acad. Sci. 203: 12-28.

Theinpont, D., F. Rochette and O.F.J. Vanporijs (1979). Diagnosing Helminthiasis through carpological examination. Janseen Research Foundation., Belgium.

Vermeulin, B., H.W. Peek, J.P. Remon and W.J.M. Landman (2004). Effect of Ibuprofen on coccidiosis in broiler chicken. Avian Dis. 48: 6876. 